\title{
Vendor selection information system on the electronic trading platform for energy supply companies
}

\author{
Rimma Zaripova ${ }^{1, *}$, Alexander Nikitin ${ }^{2}$, Yulia Hadiullina ${ }^{3}$,Elena Pokaninova $^{4}$, and Maxim Kuznetsov ${ }^{5}$ \\ ${ }^{1}$ Kazan State Power Engineering University, Kazan, Russia \\ ${ }^{2}$ Kazan National Research Technical University named after A.N. Tupolev, Kazan, Russia \\ ${ }^{3}$ Kazan Innovative University named after V.G. Timiryasov (IEML) Kazan, Russia \\ ${ }^{4}$ I.M. Sechenov First Moscow State Medical University (Sechenov University), Moscow, Russia \\ ${ }^{5}$ Kazan State Agricultural University, Kazan, Russia
}

\begin{abstract}
The main challenges for industrial companies today are to improve the competitiveness of their products and to adapt and respond quickly to changes in the external environment. Ensuring the effective functioning of an industrial enterprise is largely determined by its procurement activities, including the reliability and consistency of the procurement process. Relevance of the topic is conditioned by the fact that procurement is one of the main components in increasing of competitiveness and efficiency of the enterprise, as the major part of costs in the cost price of the finished products is concentrated exactly in procurement. Reducing costs in procurement is one of the ways to improve the efficiency of the enterprise. This advantage can be achieved through the introduction of modern information technologies, namely automation of the process of selecting suppliers on an electronic trading platform. For this purpose, an information system for selecting suppliers on the electronic trading platform has been developed, which enables a more transparent, fast, profitable and less costly selection of the cheapest and most suitable goods for the operation of energy supplying enterprises. Procurement activities are aimed at ensuring that the energy-supplying undertaking receives the right quantity and quality of raw materials, materials, goods and services at the right time, in the right place, from a reliable and trustworthy supplier with good service and at a favourable price. Automating the supplier selection process on an electronic platform is essential in today's market environment.
\end{abstract}

\section{Introduction}

The main functions of power supply companies are transmission and distribution of electricity from power plants to consumers, as well as creation of conditions for connection of new consumers.

The mission of power supply companies is to ensure reliable, high quality and affordable power supply to consumers, to create conditions for efficient operation of enterprises and organisations, comfortable and safe life of the population for the purpose of dynamic social and economic development [1-10].

Let us list the activities carried out by the division:

- Identification and collection of requirements for improvement of technical processes;

- Arrangement of requirements;

- Requirements analysis;

- Documentation of requirements;

- Coordination of requirements with the head of department;

- Software design and development;

- Implementing the software in the organization;

- Software support and assistance to technical support staff in troubleshooting bugs;
- Maintenance of software currently installed on the organization's computers;

- Monitoring the technical condition of computers;

- Support of data servers.

Current problems of energy supply utilities are unscrupulous management companies, service providers and consumer debts. The problem of unscrupulous suppliers of services and necessary goods for the operation of the enterprise is particularly acute. The enterprises are continuously working on process automation. The energy supplying enterprises also plan to switch to electronic platforms to organise trade relations, including electronic document turnover with suppliers and consumers, and selection of suppliers [11].

In the current context of developing market relations, enterprises need to conduct tenders to place orders for the supply of goods and services. The tendering procedure makes it possible to save considerable amounts of money and time for completion of transactions. The competition mechanism also increases competition in the market of suppliers of goods and services, which, in turn, improves the quality of goods and services provided to the population and strengthens the discipline of execution of transactions concluded

\footnotetext{
* Corresponding author: zarim@rambler.ru
} 
within the framework of the provision of relevant services by suppliers [12-13].

E-tendering is on the rise globally as many businesses are highlighting the advantages of using this procurement method over the traditional paper-based method. There are savings in financial resources, as well as less labour and time required to find the best supplier and conduct the procurement itself. The number of electronic trading platforms where both supplier and customer meet is increasing every year. This is explained by the fact that due to e-procurement companies can choose the right supplier most effectively and within a short period of time, as well as reduce the cost of purchasing material resources due to the difference between the initial and final contract price. With the introduction of electronic bidding, the openness and transparency of the procurement procedure is increased. Thus, the development of a supplier selection information system will enable public organisations to select suppliers safely and with better quality, without risking their monetary resources [14].

All e-tendering procedures have a characteristic feature - with minimal legal regulation, the interest of the organisers is solely to save their own money and to find the best conditions on the market. For e-procurement in the plural, there are electronic commercial tendering platforms that allow the search for and participation in commercial tenders. Two conditions are required to participate in e-commerce tenders: an electronic signature and pre-accreditation. Hence, the main feature of participation in electronic bidding is that the participant can concentrate on his/her bid rather than literally following the rules set by the organiser. A comparison of foreign and domestic procurement experiences suggests that each country is characterised by distinctive procurement practices. The similarities are the principles of e-tendering in each country, namely the achievement of the principles of fairness, transparency and efficiency in tendering. Procurement activities within an enterprise constitute an important link in generating profits. The main function of this activity is to provide the enterprise with the necessary materials at the right time, in the right quantity and at the right quality. Only with proper procurement will production function steadily [15]. To increase the efficiency of procurement activities, they need to be constantly improved. Today, modern information technology enables procurement by means of electronic trading platforms. This method of procurement will make it possible to increase employee productivity and reduce the cost of purchased materials, thereby lowering the cost of the finished product.

To compare the organisation of procurement activities on the basis of e-tendering, leading countries such as the US and EU countries can be highlighted. The following criteria were used for the comparative analysis:

- The principles of procurement through e-tendering;

- ways to place orders;

- peculiarities of bidding.

Overseas, the United States has the most experience in information support for procurement. The main principles of procurement activities in the US are:
- Achieving fairness in the bidding process (ensuring that bidders are equal in competition);

- Fighting corruption in electronic procurement;

- Economy and efficiency (ensuring the required quality of purchased materials at minimal costs).

The principle of fairness in the US is achieved by ensuring equality of participants in the e-tendering process, thereby ensuring fair competition among suppliers. Corruption is combated by creating special "black lists" of unscrupulous suppliers, with whom cooperation is further excluded. The principle of economy and efficiency of e-tendering implies ensuring the required quality of purchased materials, but at the same time with minimum costs.

In EU countries, electronic bidding is carried out on the basis of the following principles:

- the principle of transparency;

- the principle of transparency; - strict adherence to procurement procedures; - the principle of open and effective competition; - the principle of integrity in the procurement process.

- the principle of open and effective competition;

- the principle of fairness.

The principle of transparency is implemented through the availability and openness of procurement information. The principle of open and effective competition means non-discrimination in the process of electronic bidding. Fairness in e-tendering means ensuring equal opportunities for all procurement participants.

In Russia, electronic marketplaces appeared much later than abroad. But in the meantime, they have become a very popular way of purchasing amongst businesses. In Russia, electronic tenders are based on the principles of

- transparency and honesty;

- ease of bidding;

- efficiency of electronic bidding.

The principle of transparency and integrity is implemented through the confidentiality of bidders. This principle ensures that the customer is unbiased towards suppliers [16]. Convenience of tendering means the possibility to obtain necessary information promptly and to conduct tenders directly from the workplace. The efficiency principle of electronic bidding means purchasing the required raw materials with maximum savings without losing quality.

As a result of comparing tenders in different countries according to this criterion, it can be said that both in Russia and abroad there are similar principles of procurement, the common goal of which is to ensure the efficiency of e-tendering.

The main ways of placing orders in the US are as follows: "open tendering" and "direct negotiations" between the customer and bidders. "Open tendering" involves issuing a contract based on a comparison of the cost aspects of the competing bids only, without further discussion between the parties. The contracting authority prepares an "invitation to tender" and sends it to the bidders. The invitations shall include all documents necessary for the preparation of a sound bid by the tenderers. When determining the time frame within 
which the tenderers shall prepare their bids, the contracting authority shall take into account: the urgency and importance of the order, the complexity of the requirements, the expected level of co-operation and the geographical location of the tenderer. "Direct negotiations" involve the placement of orders on the basis of a review and comprehensive discussion of the proposals of one or more tenderers. The main way of informing potential tenderers of the requirements of the products to be ordered is through "requests for proposals", which are sent out similar to "invitations to tender".

In EU countries, the most commonly used methods are request for proposals and competitive negotiations. Requests for proposals shall be sent to at least three suppliers. The client (procuring entity) shall set the criteria for evaluation of the proposals, their relative importance and the way they shall be applied in the evaluation. These criteria shall relate to the relative managerial and technical competence of the supplier, the efficiency of his proposal in solving the problem posed, and its price, including the cost of operation, maintenance and repair. Competitive negotiations are confidential and all bidders who have submitted proposals and whose proposals have not been rejected are given the opportunity to participate. The contracting authority then invites the suppliers to submit their final options by a certain date, from which the best one shall be chosen.

Electronic bidding in Russia is characterised by an endless variety of forms, but the most commonly used forms are the well-known and well understood. These include tenders and auctions, which can be either upward or downward. A tender is a method of determining the supplier (contractor, contractor), in which the winner is the bidder who offers the best terms and conditions of the contract. An auction is a method of determining the supplier (contractor, performer), in which the winner is the participant of procurement who offered the lowest price of the contract. However, these methods of procurement may not necessarily be open to the public. The organiser may decide to hold these tenders exclusively among invited bidders, in which case these tenders are closed. When looking at procurement methods in different countries, it can be concluded that each country uses different methods of placing orders.

The following types of electronic trading platforms are distinguished:

1. B2G (business-to-government) are federal (budgetary) trading platforms. These are marketplaces where the customers are enterprises and state institutions. These marketplaces are used for public procurement.

2 B2B (business-to-business) are commercial electronic marketplaces. On these marketplaces, the customers are commercial organizations.

3. Buyer-driven - these are electronic marketplaces that are created and maintained by buyers. In order to optimize their purchasing process, one or several large companies set up their own marketplace to attract a large number of suppliers.
4. Suppliers-driven or seller-driven are marketplaces that are created and maintained by large suppliers. These companies are interested in expanding sales channels for their products.

5. Thirdparty-driven are marketplaces created and maintained by a third-party intermediary between sellers and buyers. This category is the most numerous. This type of marketplaces are subdivided into industry and multiindustry marketplaces. Branch platforms are created for one certain enterprise, for example, for Gazprom. Multi-sector platforms, on the contrary, are not limited to the nomenclature of only one enterprise.

6. $\mathrm{C} 2 \mathrm{C}$ (consumer-to-consumer) platforms are ecommerce platforms between individuals. The e-auction site ebay.com is a prime example of this. On such marketplaces, individuals can sell goods to other individuals.

7. B2C (business-to-consumer) - these are retail ecommerce systems where the seller is a company and the buyers are mostly individuals. Most commonly, these are online shops such as ozon.ru, amazon.com and others that sell a large range of consumer goods.

E-Platform eBay is a great example of an online marketplace; literally anything can be bought there. Because e-marketplaces offer real convenience to consumers, the number of marketplaces with different features has grown significantly over the past few years. Because users have access to suppliers' inventories electronically, the marketplace does not need to own the resources before offering them to consumers. All products and information about them are available to consumers in real time, available on the online shop's website or app. It is a much wider and more transparent range of products than any conventional real shop. Consumers don't like to buy all the things they need in one shop. It is much easier for them to download an app that offers a wider range at once than to drive around town looking for the right shop. This is one of the main advantages of e-platforms. Marketplaces have some disadvantages. Because there are so many sellers offering products, the information about them is often not accurate, and the speed of delivery by sellers varies [17].

Procurement is therefore one of the main components in increasing the competitiveness and efficiency of a business because it is where most of the costs in the cost of the finished product are concentrated. Reducing costs in procurement is one of the ways to improve the efficiency of the enterprise. This advantage can be achieved through the implementation of information system for selecting suppliers on an electronic trading platform, due to which the energy-supplying company receives on time, in the right quantity and quality, raw materials, goods and services from a reliable and trustworthy supplier with good service and at a favourable price. The development of a supplier selection information system will make it possible to select the cheapest and most suitable goods for the operation of energy supply companies in a more transparent, fast, profitable and cost-effective manner. We will also identify the advantages and disadvantages of using it [18]. 


\section{Materials and methods}

Let us consider the process of implementing an information system for selecting suppliers on an electronic trading platform for energy supply companies. Visual Studio Code software product was chosen as a development environment. Visual Studio Code is a source code editor developed by Microsoft for Windows, Linux and macOS. It is positioned as a "lightweight" code editor for cross-platform web and cloud application development. It includes a debugger, tools for working with Git, syntax highlighting, IntelliSense and tools for refactoring. It has extensive customization options: custom themes, keyboard shortcuts, and configuration files. Distributed free of charge, it is developed as open source software.

A bunch of HTML5 \& CSS3 \& JavaScript was proposed as standards for web applications development. This bundle is used for front-end development of the user part of the website. With HTML5, the structure of a web page such as headings, paragraphs etc. is created. CSS3 allows you to create design styles for the look of the page and its description such as colours and font options. JavaScript is responsible for handling user requests and responsiveness of the interface. It is also used to send requests to the server, download the necessary data, input and output messages and many other useful functions. Let's take a closer look at the tools used to develop web applications.

HTML5 is a platform that is designed to create a variety of client web applications that use audio, video, graphics, animations, and more. HTML5 provides a number of elements that simplify the structure of pages. Thanks to the simplified markup needed for creating web pages and combining all the required CSS and JavaScript code, users connected to the developed website can easily browse the pages at high speed, even when connected to the internet at a low data transfer rate. Because of the semantic markup structure, the HTML5 language also provides the ability to represent the website elements in distinct logical areas, using new tags and semantic partitioning. And the ability to support native audio, video, graphics, and animation frees users from the need to download additional plug-ins to view the content of web pages.

Formal language for describing the appearance of the document. CSS3 allows you to create visual effects and even animation, and quite a high level. It is the cascading style sheets, describing the features of the appearance of a web document, allows you to create the most attractive design of web pages.

Client-side programming languages are used to create dynamic content and implement client-side functionality. JavaScript is defined as the standard language for web client programming. One of the key features of client-side programming languages is that they are executed in the browser and do not have direct access to the file system, and therefore to databases. This includes JavaScript. The language is object-oriented and, as an object language, supports object technology for representing a document, or representing a web document as a group of objects on some substrate which is called a window. There can only be one window, and it has a number of properties. The window contains the document, which also has a number of properties, and the elements are already arranged in a certain order on the document. The order of the elements can be broken by using CSS styles, which can be controlled by JavaScript commands.

The jQuery framework, which is the most widely used framework today, allows all the functions of clientside web development and greatly extends and simplifies the code thanks to the functions developed in it. jQuery UI is based on the framework and focuses on the design of the main elements of the website interface (menus, text blocks, galleries, etc.). The use of frameworks in development is a characteristic feature of a modern website and is nowadays a necessary element. We have developed a new framework based on jQuery which handles the dynamic design of the client side of the website. Bootstrap is a popular framework that allows you to create static websites and web applications quickly and efficiently. It is essentially a free toolkit which allows you to use HTML, CSS and JavaScript. In back-end development, the most common is the PHP \& MySQL bundle. PHP has enough tools to organize a fullscale work with the database.

Modern dynamic websites always use a database to store various content, as well as to implement its functions. The most common relational database management system is MySQL. The chosen database management system is quite easy to use and has many advantages, such as multi-threading, support for multiple simultaneous queries and flexible support for number formats, variable length strings and timestamps, which is especially important when the number of users accessing the server where the site will be located is high.

The customer can fill in the information system database with data on requirements and products, and register on the website followed by a questionnaire.

The Supplier, like the Customer, can also fill in the database of the information system with data on requirements and goods, register on the website and then fill in the questionnaire, as well as view order requirements, goods characteristics and edit prices and descriptions of goods.

The information system adds the customer and supplier to the database, browses order requirements, product specifications and edits prices and descriptions, compares the requested product and the product available in the database, notifies when new offers are available, handles invoicing for payment, and notifies customers. In a distributed model, each division of the energy-supplying companies carries out the necessary purchases independently. In a centralised model, there is a procurement centre where purchase requests from divisions are pooled together. The pros and cons of both schemes are clear: the distributed model is very flexible, but it is more costly. The centralised model, while providing low prices through bulk purchasing, is less mobile and does not always take into account the nuances in the requisitioning of goods and services. 


\section{Results}

An electronic marketplace sourcing information system is a hardware and software system that enables interaction between suppliers of services or goods and customers at all stages of the transaction online. The owner of a marketplace does not own any resources; its task is to act as an intermediary between the two people making the transaction. Typically, all organisations involved in procurement face the problem of finding a bona fide supplier of goods or services [19]. A particular challenge is identifying the most suitable supplier within a tight timeframe for the needs of the business, who will also offer favourable terms and conditions to both parties in the trade deal.

Electronic marketplaces help businesses save significant amounts of money and time investment. An electronic trading platform also provides the opportunity to organise suppliers and consumers of a variety of goods and services into one information system for trading transactions and offers participants a range of services to help improve the effectiveness of their business relationship.

Customers get an opportunity to conduct electronic tenders - tenders, auctions, requests for prices and offers, optimising costs, and suppliers can participate in ongoing procurements, place information about products and services offered. More often than not, the placement of tenders is handled by specialised companies who, in addition to placing the information on the trading floor, process the result and possibly even determine the winner of the procedure [20-21].

The information system for selecting suppliers on the electronic trading platform is designed to enable the customer, without having to contact the purchaser, i.e. a third party, to purchase the goods of interest using the electronic sales system [22]. The purchaser, as a third party, may not be entirely honest and interested in finding the right product, for example, he may be poached by competitors and then buy a lower quality product or even worse, a resource that does not suit the customer at all. This would not only lead to unnecessary costs for unnecessary goods, but also to a huge waste of time.

Based on the analysis of the subject area to design an information system for selecting suppliers in the electronic trading platform for power supply companies the following entities can be distinguished: the Customer, the Purchaser, the Supplier, the Contract, the Order.

Entity "Customer" is characterized by attributes "Telephone", "Address", "Name". The key of this entity is attribute "Phone", because each user has his own phone number. Entity "Procurer" is characterized by attributes "Company", "Name", "Position". The entity "Supplier" is characterized by attributes "Company", "Title", "Contact", "Name". The entity "Contract" is characterized by attributes "Number", "Signatures", "Terms". Entity "Order" is characterized by attributes "Number", "Requirements", "Terms".

Since the buyer is not particularly interested in choosing the highest quality goods for the customer, and also the possibility of bribery of the buyer by competitors cannot be excluded, the procurement system should be improved. Also, the purchaser may mistakenly select a product that does not meet the customer's requirements, which in turn leads to unnecessary costs and loss of time. In addition, the customer spends a certain amount of time searching for the right buyer and then explaining his financial capabilities and requirements for the right product.

The information system allows the customer to specify, through a user-friendly interface, the necessary requirements for the order, and then the site itself will select the right products at the lowest price. It will also remove third parties and various intermediaries from the relationship chain and make the information about the orders and the equipment in the company more confidential.

The requirements for a supplier selection information system are:

- user-friendly interface;

- autonomy of operation;

- security of data storage;

- cost-effectiveness of use.

The objectives of an electronic marketplace sourcing information system are as follows:

- quick search by name;

- customer registration and account creation;

- creation of sorting of suppliers by popularity, price, and rating;

- selecting buyers by category; placing an order;

- analysis of goods on the platform;

- selection of goods according to specified requirements;

- exclusion of a third party from the procurement process;

- confidential transactions between supplier and customer;

- Transparent transactions and operations.

\section{Conclusion}

The efficiency of energy utilities depends directly on information technology. The technology advances today include e-tendering. They involve information and economic interaction between companies on electronic trading platforms via the Internet and make it possible to build efficient trading and purchasing activities [23].

Advantages of an information system for selecting suppliers on an electronic trading platform:

- Organisation of transparent competitive bidding in electronic form

- Saving of costs and obtaining of better terms from suppliers as a result of procurement procedures

- Attracting suppliers and selecting the most qualified, bona fide ones

- Elimination of paperwork, increasing the speed of procurement procedures

- Facility to swiftly adjust the business logic of procurement processes to meet current business requirements 
- Procurement of complex products, organization of supply chain and joint purchases of subdivisions or enterprises of the holding company.

- Selling unclaimed assets at higher prices.

Let's look at the advantages of using the information system for selecting suppliers on an electronic trading platform for the customer and supplier [24-25].

Advantages for the customer: wide range of quality products and services at affordable prices; increasing the number of suppliers; faster bidding due to the use of electronic documents; effective and reliable technology of electronic bidding; significant reduction in procurement prices; transparency of transactions.

Advantages for the supplier: wide geography of electronic bidding; opportunity to reach customers from other regions; reduced time and financial costs of preparation of bidding documents due to maintenance; accreditation for 3 years at electronic trading platform; opportunity to see in real time all price offers of competitors; opportunity to offer price which is more attractive to a customer; fair competition; increased responsibility of bidders due to electronic signature use; refusal from contracting for the first and second tenders.

The implementation of a supplier selection information system on an electronic trading platform will also make the procurement process more transparent. Monitoring of enterprise resources will become much easier. Consequently, there will also be fewer disruptions in operations, which in turn will save a huge amount of financial resources.

\section{References}

1. L.V. Plotnikova, R.R. Giniyatov, S.Y. Sitnikov, M.A. Fedorov, R.S. Zaripova, IOP Conf. Ser.: Earth Env. Sci., 288, 012069 (2019)

2. R.S. Zaripova, E.A. Saltanaeva, N.G. Bikeeva, E.V. Priimak, IOP Conf. Ser.: Earth Env. Sci., 288, 012129 (2019)

3. V.I. Sitas, A.V. Fedyukhin, I.G. Akhmetova, A. Mitrofanov, S.O. Makoev, A. Asadpoori, A.A. Sinitsyn, E.A. Kikot, International J. of Civil Engineering and Technology, 10 (2), 2106 (2019)

4. I.N. Voytyuk, A. V.Kopteva, A.N. Skamyin, A.N. "Emergency Response Plan" Automated System for Oil Production and Transportation Enterprises, Journal of Ecological Engineering (2020)

5. J.E. Shklyarskiy, D.E. Batueva, The influence of external climatic factors on the accuracy of the forecast of energy consumption, E3S Web of Conferences 140,04014 (2019)

6. I.I. Rastvorova, Assessment of the consumers' contribution to the deterioration of the electrical power quality, IOP Conference Series: Materials Science and Engineering 643(1), 012010 (2019)

7. C. Savard, E.V. Iakovleva, A suggested improvement for small autonomous energy system reliability by reducing heat and excess charges, Batteries 5(1),29 (2019)
8. E. Bazukova, Y. Vankov, Increasing the reliability of thermal energy transportation systemstaking into account forecasting the properties of thermal insulation during operation, E3S Web of Conferences 216,01078 (2020)

9. N. Rydalina, E. Antonova, I. Akhmetova, (...), V. Bianco, A. Fedyukhin, Analysis of the efficiency of using heat exchangers with porous inserts in heat and gas supply systems, Energies 13(22),5854 (2020)

10. A. Kulachinskaya, I.G. Akhmetova, V.Y. Kulkova, S.B. Ilyashenko, The challenge of the energy sector of russia during the 2020 covid-19 pandemic through the example of the republic of Tatarstan: Discussion on the change of open innovation in the energy sector, Journal of Open Innovation: Technology, Market, and Complexity 6(3),60 (2020)

11. I.G. Akhmetova, N.D. Chichirova, J. of Engineering and Applied Sci., 11 (13), 2930 (2016)

12. V. Kryukov, N. Petrov, State regulation of investment processes, The Economist, 5, 91-96 (2008)

13. A.A. Polidi, Regional Economy: Theory and Practice, 3 (186), 10 (2011)

14. A.P. Kuznetsov; A.V. Kalyashina, H.-J. Koriath, T. Langer, Procedia Manufacturing, 21, 525-532 (2018)

15. S.A. Solovev, O.V. Soloveva, B.S. Gilmurahmanov, A.A. Lamberov, J. Phys.: Conf. Ser., 1399 (5), 055022 (2019)

16. R. Zaripova, A. Porunov, R. Zinurova, R. Galyamov, G. Stepanova, Adv. Econom. Business Manag. Res., 131, 663 (2019)

17. O.V. Soloveva, S.A. Solovev, R.R. Yafizov, IOP Conf. Ser.: Mater. Sci. Eng., 709 (3), 033064 (2020)

18. A.E. Kremin, I.G. Akhmetova, ACM International Conf. Proceeding Ser., 46 (2020)

19. M. Tyurina, A. Porunov, R. Zaripova, A. Gaynetdinova, V. Kosulin, Adv. Econom. Business Manag. Res., 131, 648 (2019)

20. O.V. Soloveva, S.A. Solovev, R.R. Khusainov, J. Phys.: Conf. Ser., 1399 (2), 022059 (2019)

21. A.V. Chupaev, R.S. Zaripova, R.R. Galyamov, A.Y. Sharifullina, E3S Web Conf., 124, 03013 (2019)

22. O.V. Soloveva, S.A. Solovev, R.R. Yafizov, Ecol. Ind. Rus., 24 (9), 39 (2020)

23. O. Rocheva, L. Khadiullina, R. Zaripova, G. Hamatgaleeva, V. Kosulin, Adv. Econom. Business Manag. Res., 131, 640 (2019)

24. O. Soloveva, S. Solovev, R. Khusainov, R. Yafizov, Adv. Int. Sys. Comp., 1259 AISC, 371 (2021)

25. R. Zaripova, M. Tyurina, O. Rocheva, A. Chupaev, A. Sharifullina, Adv. Econom. Business Manag. Res., 131, 271 (2019). 